\title{
1 Experimental Study on Shear Performance of RC 2 Beams Strengthened with NSM CFRP Pre- stressed Concrete Prisms
}

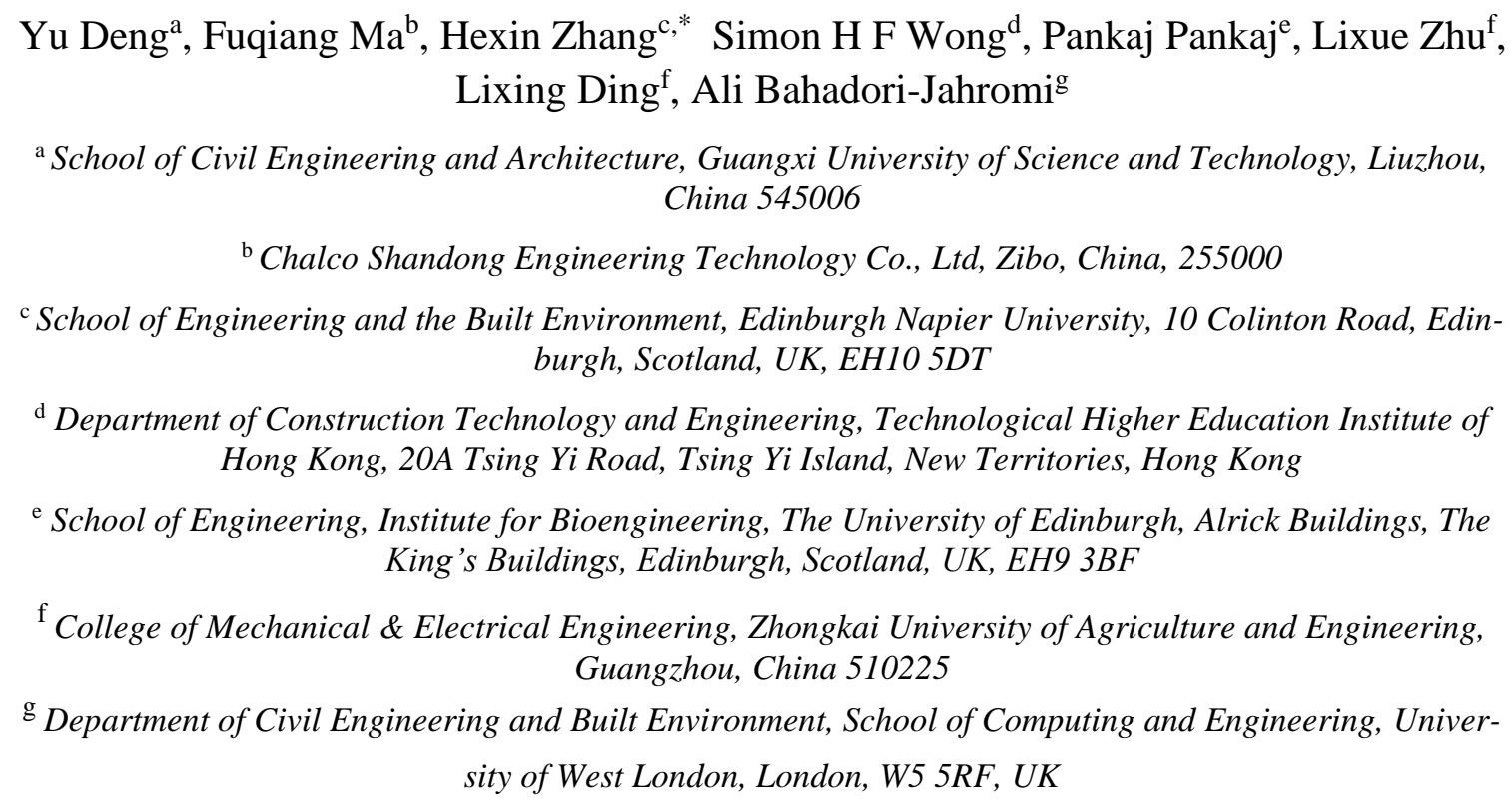

${ }^{\mathrm{b}}$ Chalco Shandong Engineering Technology Co., Ltd, Zibo, China, 255000

${ }^{\mathrm{c}}$ School of Engineering and the Built Environment, Edinburgh Napier University, 10 Colinton Road, Edinburgh, Scotland, UK, EH10 5DT

${ }^{\mathrm{d}}$ Department of Construction Technology and Engineering, Technological Higher Education Institute of Hong Kong, 20A Tsing Yi Road, Tsing Yi Island, New Territories, Hong Kong

${ }^{\mathrm{e}}$ School of Engineering, Institute for Bioengineering, The University of Edinburgh, Alrick Buildings, The King's Buildings, Edinburgh, Scotland, UK, EH9 3BF

${ }^{\mathrm{f}}$ College of Mechanical \& Electrical Engineering, Zhongkai University of Agriculture and Engineering, Guangzhou, China 510225

${ }^{\mathrm{g}}$ Department of Civil Engineering and Built Environment, School of Computing and Engineering, University of West London, London, W5 5RF, UK

Abstract: This paper presents an experimental investigation of the shear performance of RC beams strengthened with near surface mounted (NSM) carbon fibre reinforced polymer (CFRP) prestressed concrete prisms (PCPs). The shear behaviour of strengthened beams can be affected by several design variables. In this research, the effect of the following parameters were considered: the prestress level, inclination and spacing of the CFRP-PCPs, and material type of the prism. The control beam had conventional shear steel reinforcement only while the other seven beams were shear strengthened with CFRP-PCPs by varying design parameters mentioned above. All the beams were tested under monotonic loading until they reached the failure load. The experimental results showed that the NSM CFRPPCPs strengthening technique improves the shear performance of the beams effectively. The strengthened beams that applied the CFRP-PCPs at an inclination of $45^{\circ}$ were more efficient in improving the shear capacity compared to vertical CFRP-PCPs. The shear capacity

\footnotetext{
* Corresponding author

E-mail address: j.zhang@napier.ac.uk (Hexin Zhang)
} 
1 and deformation were enhanced with the increase of prestressing levels of CFRP rods and

2 the decrease of CFRP-PCPs spacing. The failure modes of the strengthened beams were

3 influenced mainly by the spacing and the inclination of the CFRP-PCPs. Moreover, the ma-

4 terial type of the prism had little influence on the effectiveness of shear strengthening. The

5 analytical model presented was developed to estimate the shear contribution of NSM CFRP-

6 PCPs and the model was found to predict the shear capacity of the tested beams well.

8 Keywords: Shear strengthening; CFRP-PCPs; NSM technique; Experimental; Analytical 9 model

\section{1. Introduction}

13 Shear failure in reinforced concrete $(\mathrm{RC})$ structures is generally brittle in nature and

14 needs to be avoided via appropriate design. Ageing reinforced concrete structures usually

15 exhibit shear cracks due to factors such as natural disasters, regular and unforeseen loads,

16 loads not considered in the original design, and inadequate concrete strength due to produc-

17 tion or ageing 3.2. Therefore, an efficient and economic shear strengthening technique is

18 required to solve the shear-deficiency problem in the existing damaged and ageing RC struc-

19 tures.

20 In recent decades, carbon fibre reinforced polymer (CFRP) composite has been widely

21 used for shear and flexural strengthening of RC structures due to its various advantages, for

22 instance, high strength to weight ratio, high fatigue strength, non-corroding properties, and

23 high chemical resistance [3-5]. Therefore, a strengthening technique that applies the CFRP 
1 bars and laminates can effectively solve the problems that come with conventional strength-

2 ening techniques such as steel jacketing and concrete enlargement [6, 7]. The CFRP

3 strengthening technique includes the external bonding $(\mathrm{EB})$ technique with CFRP laminates,

4 near surface mounted (NSM) method with CFRP laminates or rods, and external confine-

5 ment (EC) using CFRP sheets [8-11]. Many researchers have suggested that the strengthen-

6 ing technique with CFRP rods or laminates can improve the flexural and shear behaviour of

7 the deficient beams effectively [9, 12-14].

8 The NSM strengthening technique involves embedding the CFRP rods or laminates

9 into grooves that are pre-cut on the concrete surface and bonding them to the concrete with

10 an epoxy adhesive. It is the most effective CFRP strengthening method due to the following

11 advantages: (a) it provides a larger bond area and higher confinement by the surrounding

12 concrete, (b) it requires minimal installation time, (c) the concrete cover can protect the

13 CFRP rods from vandalism, mechanical damage and fire [15, 16]. El-Hacha and Rizkalla

14 reported that the NSM strengthening technique using CFRP bars and strips significantly

15 improved the stiffness and provided a higher flexural capacity of RC beams compared with

16 the EB strengthening technique [17]. Rahal and Rumaih tested the shear capacity of four

17 RC T-beams strengthened with NSM CFRP bars and conventional steel reinforcing bars for

18 a comparative study. The study showed that the NSM strengthening increased the ultimate

19 shear capacity and cracking shear load by $37 \%-92 \%$ and $23 \%-85 \%$, respectively. The NSM

20 CFRP bars also reduced the width of the diagonal cracks and improved the ductility of the

21 test regions [16]. Kuntal and Chellapandian studied the behaviour of the NSM technique to 
1 strengthen the shear capacity of prestressed concrete beams and revealed that NSM CFRP

2 laminates oriented at $45^{\circ}$ is more efficient in improving the shear capacity of beams in both

3 configurations: with or without vertical stirrups [33]. Another very recent study from this

4 research team aims to investigate the efficiency of different bonding agents on the NSM

5 shear CFRP laminate strengthened high strength prestressed concrete beams. The beams

6 were strengthened with NSM CFRP laminates which are oriented at 45-degree configura-

7 tion and the beams are assessed by the three-point bending test. Experimental results re-

8 vealed a similar performance between the high strength cement grout and geopolymer mor-

9 tar but both are less efficient than the epoxy resin [34]. Some studies have also shown that

10 the NSM CFRP shear strengthening technique can reduce the debonding failure which is

11 commonly observed in the EB strengthening technique and it can enhance the shear re-

12 sistance of RC beams significantly when compared with other strengthening techniques [13,

$1316,18,19]$.

14 The NSM strengthening using prestressed CFRP technique has the advantages of both

15 the NSM and prestressing strengthening techniques. Many investigations have been con-

16 ducted on the innovative strengthening technique using NSM prestressed CFRP rods or

17 laminates to strengthen the RC beams [20-23]. These RC beams showed an increase of up

18 to $79 \%$ in the ultimate flexure load compared to the control beam, as reported by Badawi

19 and Soudki [20]. The prestressed strengthened beams exhibited a higher cracking load and

20 lower deflection compared with the corresponding non-prestressed beams. Jung et al. [24]

21 studied prestressed strengthening and concluded that the crack and yield loads increased 
1 with a higher level of prestress. However, the disadvantages of the NSM prestressed

2 strengthening technique should be noted; the prestressing system cannot be removed until

3 the filler is cured, and the anchorage system is costly. The strengthening technique that

4 applies the carbon fibre reinforced polymer prestressed concrete prisms (CFRP-PCPs) is a

5 good solution to these problems and is expected to improve the shear performance signifi-

6 cantly.

CFRP-PCPs are bars of a small cross-section made of high-strength concrete that is

8 concentrically pre-tensioned by a single CFRP bar [25]. The detailed fabrication method of

9 CFRP-PCPs is detailed in Section 2. Previous research confirmed that beams reinforced

10 with PCPs demonstrates superior performance before the cracking of the prisms and has a

11 smaller deflection than control beams at ultimate limit state. The cracking load and flexural

12 behaviour, under the service load condition, of these beams (strengthened with the NSM

13 CFRP-PCPs) was improved with the increase of the prestress level of the prisms [25-28].

14 However, to date, there have been only a few studies on the shear strengthening of beams

15 with NSM CFRP [29-32] but no study with NSM CFRP-PCPs. Hence, the current study

16 aims to investigate the shear performance of beams strengthened by NSM CFRP-PCPs un-

17 der service and ultimate loads. A total of eight simply supported beams with the same cross-

18 section were tested under monotonic four-point loading to rupture. The shear behaviour and

19 failure mode were observed and analysed. The impacts of different design parameters on

20 the test results were analysed and are presented in this paper. An analytical model to identify 
1 the contribution of the CFRP-PCPs in shear resistance is proposed and the results agree well

2 with the experimental study.

\section{2. Experimental programme}

6 Before discussing the details of the experimental programme, it is necessary to discuss

7 how the ultra-high performance concrete (UHPC) prism are strengthened by the prestressed

8 CFRP and how this composite enhanced the shear capacity of the beam. If the UHPC prism

9 is not prestressed, and the CFRP rod simply just embedded inside, the overall bending

10 strength of this composite will be the normal composite strength without any enhancement

11 as the threshold factor is still the relatively low tensile strength of the UHPC. Furthermore,

12 when they are placed in the shear-tension direction in a shear span, under the shear-tension

13 force, the cracks in the UHPC prisms will occur at its maximum tensile strength and that

14 marks the start of the failure. The situation will be completely different if the CFRP rod is

15 prestressed and maintained prestressed until the UHPC prism cast around it fully cured

16 (CFRP-PCPs). Firstly, the bending strength will be increased as the prestressed CFRP rod,

17 once released, will shrink back and pull the UHPC prism together with it, thus creates a pre-

18 compressed status inside the UHPC prism. This compressive stress will counteract with the

19 tensile stress generated by the bending moment and enhanced the overall bending strength

20 of the composite prism. Secondly, when this CFRP-PCPs are placed along the shear-tension

21 direction, the destructing tension force will need to overcome the prestressed compression 
1 force first inside the UHPC prism before it takes any tensile force, and that will not only

2 increase the shear capacity but also will reduce the cracks in the prisms and the concrete

3 glued around them. Finally, strengthened by prestressing, the CFRP-PCPs are also acting as

4 stronger dowels and enhance the overall shear capacity of the beam.

\subsection{Parameters of specimens}

A total of eight RC beams were designed and cast in this experimental investigation.

8 The un-strengthened beam (CSB), reinforced with steel stirrups only, was tested as a control

9 beam to compare its shear behaviour with that of other beams strengthened with NSM

10 CFRP-PCPs. The prestress level, inclination and spacing of the CFRP-PCPs, and material

11 type of the prism were considered and compared to investigate the effectiveness of shear

12 strengthening with different design details. The design parameters of the tested beams are

13 listed in Table 1.

All tested beams were $250 \mathrm{~mm}$ in depth and $170 \mathrm{~mm}$ in width. The beams had an

15 overall length of $2200 \mathrm{~mm}$ and were reinforced with the same longitudinal and transverse

16 steel reinforcement. The beams were reinforced in tension with two longitudinal steel bars

17 of $22 \mathrm{~mm}$ diameter and the percentage of the tensile steel bars was $3.2 \%$. Three steel bars

18 of $10 \mathrm{~mm}$ diameter were applied in the compression zone. The shear span ratio (i.e. the ratio

19 of beam shear span to the effective depth of the beam) of beams was 2.9 so that the arch

20 effect can be neglected and the shear failure of the beams can occur as expected. The $6 \mathrm{~mm}$

21 steel stirrups spaced at $200 \mathrm{~mm}$ were applied in the flexural span. The shear span used 6 
$1 \mathrm{~mm}$ steel stirrups spaced at $300 \mathrm{~mm}$ and a steel stirrups ratio of $0.11 \%$ [32]. The detailed

2 design and configuration of the specimens are shown in Fig. 1.

$4 \quad 2.2$ Material properties

The concrete, reinforcement steel, UHPC and epoxy mortar are all tested according to

6 the National Standard of China specified in Table 2. The tested beams were cast with a

7 concrete mix produced by the local mixing plant in Liuzhou City in China. Nine concrete

8 cubes $(150 \mathrm{~mm} \times 150 \mathrm{~mm} \times 150 \mathrm{~mm})$ were also cast and cured under the same conditions

9 to test the compressive strength of concrete. After curing for 28 days, an average compres-

10 sive strength of $30.76 \mathrm{MPa}$ was obtained from the standard compressive tests. Additionally,

11 a tensile strength of $3.02 \mathrm{MPa}$ and modulus of elasticity of $3.27 \times 10^{4} \mathrm{MPa}$ were also ob-

12 tained. Three standard samples were prepared for each type of reinforcement. The test re-

13 sults are listed in Table 2. The prestressed CFRP rod of $7 \mathrm{~mm}$ diameter, the UHPC and the

14 epoxy resin mortar were all provided by Liuzhou OVM Machinery Co. Ltd. Nine UHPC

15 cubes $(100 \mathrm{~mm} \times 100 \mathrm{~mm} \times 100 \mathrm{~mm})$ were also cast and cured under the same conditions

16 for the CFRP-PCPs prefabrication. Nine epoxy mortar cubes $(40 \mathrm{~mm} \times 40 \mathrm{~mm} \times 160 \mathrm{~mm})$

17 were also cast and cured under the same conditions for CFRP-PCPs installation. The me-

18 chanical properties of the CFRP rod were specified by the Product Quality Certificates pro-

19 vided by the manufacturer detailed in Table 2 . The specific properties of the materials ap-

20 plied to the tested beams are summarized in Table 2.

22 2.3 The fabrication of CFRP prestressed concrete prisms (CFRP-PCPs) 
2 and cast with the UHPC or epoxy resin mortar as shown in Fig. 2. The fabrication method 3 of CFRP-PCPs was as follows: the grooves which had a cross section of $30 \mathrm{~mm} \times 30 \mathrm{~mm}$ were pre-cut on both sides of the

a) The CFRP rods were placed concentrically on the stretching pedestal and pre-tensioned by the prestressing apparatus as shown in Fig. 2. During the prestressing procedure, the strain and the prestress force were monitored through strain gauges mounted on the rod and the load cell placed at each end of the beam. The prestressing force at jacking was $23.1 \mathrm{kN}$ and $38.5 \mathrm{kN}$, respectively. The prestressing force was $30 \%$ and $50 \%$ of the ultimate strength of the CFRP rod. The data was collected by the data acquisition system (DAQ). The prestressed CFRP rods were maintained concentrically using the tightened anchor nuts and cast with the UHPC or epoxy resin mortar to form a whole prism.

b) After casting, the CFRP-PCPs were cured for 15 days in a wet condition. The anchor nuts could be removed when the CFRP-PCPs reached the design capacity. Finally, CFRP-PCPs with a cross-section of $25 \mathrm{~mm} \times 25 \mathrm{~mm}$ were obtained and ready to be applied on both sides of the beam for shear strengthening of the tested beams.

\subsection{NSM strengthening technique with CFRP-PCPS}

The tested beams met the design strength requirement after curing for 28 days. Then shear span of the strengthened beams. The grooves were cleaned to remove dust so that it 
1 was easy to form a strong bond between the prisms and the concrete. Following that, the

2 epoxy resin was poured into the grooves up to halfway and the CFRP-PCPs were embedded

3 into the grooves on the concrete surface. The epoxy resin had a tensile strength of $22.5 \mathrm{MPa}$

4 and compressive strength of $90 \mathrm{MPa}$ (provided by the manufacturer). The CFRP reinforce-

5 ment ratio are $0.17 \%, 0.11 \%, 0.16 \%, 0.24 \%$ respectively. The strengthened beams were

6 cured for at least 7 days under the standard condition to ensure the design bonding strength

7 was attained.

\subsection{Test setup and loading procedure}

10 The tested beams were simply supported and subjected four-point monotonic loading

11 using the servo-hydraulic controlled MTS actuator. All the tested beams were loaded with

12 force-controlled at a rate of $3 \mathrm{kN} / \mathrm{min}$. The applied load was converted to two-point loads

13 through a steel spreader beam. After the appearance of the first crack in the beam being

14 tested, the beams were tested in displacement-control mode at a rate of $1.2 \mathrm{~mm} / \mathrm{min}$, the

15 increase in load was paused intermittently at intervals of $10 \mathrm{kN}$ to observe and maintain

16 constant for five minutes to allow the documentation of the position, length and opening of

17 the shear cracks. There is no noticeable increase in deformation observed during the break.

18 The strain gauges were located at the middle of both tensile and compressive bars and the

19 shear reinforcement in shear span to monitor strain of the steel bars and CFRP rods during

20 the test. A total of five strain gauges were also mounted on all tested beams evenly distrib-

21 uted on the surface of the middle span to measure the strain of the concrete during the load- 
1 ing process. To measure the deflection of the beams, five linear variable differential trans-

2 ducers (LVDT) were located at the load points, the supports and the mid-span of beams.

3 The strain data was collected and recorded from the beginning of loading to failure using

4 the data acquisition(DAQ) system. The test setup and instrumentation details are shown in $5 \quad$ Fig. 3.

6

\section{$7 \quad 3$ Experimental results and discussion}

\section{$8 \quad 3.1$ The failure modes}

9 Figure 4 shows the failure modes for the control beam and of beams strengthened by

10 the NSM CFRP-PCPs technique. During the loading process, first-cracking occurred in the

11 mid-span (strengthened beams) or the sections close to the loading points (control beam).

12 As the applied load was increased, the vertical cracks appeared in shear span and developed

13 to the critical diagonal crack propagating toward the loading points. The development of

14 shear cracks was effectively hindered by NSM CFRP-PCPs and steel stirrups. However,

15 after the first crack in NSM CFRP-PCPs, the crack broadened rapidly and developed toward

16 the compressive zone of the beam-top.

17 In the test of the ultimate limit state, the primary failure modes of specimens all 18 demonstrated or initiated by the shear-tension (diagonal-tension) failure. Three accompa-

19 nied secondary failure types accelerated the rupture of the beams after the structures being

20 weakened by the shear-tension cracks. The first secondary failure type was shear-compres-

21 sion failure characterized by the concrete crushing under the loading points because the 
1 shear crack went across the prisms and decreased the shear-compression zone of the beams.

2 This failure mode mainly occurred in the control beam and the beams strengthened with

3 CFRP-PCPs spaced at $300 \mathrm{~mm}$. The second type was debonding of the CFRP-PCPs across

4 the shear cracks and the concrete crushing under the loading points characterized the second

5 mode. In general, the initial shear cracks developed between two prisms in the beams

6 strengthened with vertical CFRP-PCPs spaced at $200 \mathrm{~mm}$. The shear cracks propagated and

7 went across the CFRP-PCPs as the load increased, which led to the detachment of concrete

8 along with the debonding of CFRP-PCPs. The third type was bending failure, which was

9 observed in the beam FCSB2-b, strengthened with $45^{\circ}$ NSM prestressed CFRP-PCPs

10 spaced at $200 \mathrm{~mm}$. The propagation of shear cracks was suppressed effectively by the

11 CFRP-PCPs and the mode of failure was flexure dominant. The beam had several flexure

12 cracks and was less brittle than the other beams. As shown in Fig. 4, the application of NSM

13 CFRP-PCPs arrested the propagation of shear cracks effectively so that the ultimate capacity

14 of strengthened beams was improved significantly compared with that of control beam. The

15 strengthened beams exhibited more ductile behaviour due to effective control of shear

16 cracks by NSM CFRP-PCPs as well as steel stirrups.

\subsection{Load-displacement relationship}

20 The load-displacement curves of the control beam and strengthened beams are pre-

21 sented in Fig. 5. The displacement is measured by the displacement sensor No 1,2 and 4.

22 The value of the displacement is calculated in this way: LVDT 4 - (LVDT 1+LVDT 2)/2. 
1 The locations of the displacement sensors are shown in Fig. 1(a). The load-displacement

2 curves of all specimens were similar until the shear cracks initially appeared in the control

3 beam. The displacement of the control beam increased relatively rapidly due to the decrease

4 of stiffness. The shear-strengthened RC beams with NSM CFRP-PCPs continued to carry

5 increased loads. When the first cracking occurred in the strengthened beams, the decrease

6 of stiffness was smaller than in the control beam because the propagation of shear cracks

7 was hindered by the CFRP-PCPs. This indicated that the CFRP-PCPs bridge the shear crack

8 thus providing load resistance, which has also been reported in the previous experimental

9 research [19]. All the experimental results of the tested beams are summarized in Table 3.

10 The first shear crack of the control beam occurred at $40 \mathrm{kN}$ while the strengthened beams

11 had a higher load level, ranging from $75 \mathrm{kN}$ to $130 \mathrm{kN}$. This shows that the NSM CFRP-

12 PCPs configurations can delay the occurrence of shear cracks effectively and convert the

13 sudden brittle shear failure to shear-compression mode. Thus, the beams strengthened using

14 the NSM CFRP-PCPs technique have higher stiffness and load-carrying capacity than the

15 control beam with only conventional steel reinforcement.

16 The ultimate load of the control beam was $156.13 \mathrm{kN}$. The shear strength of all the

17 strengthened beams was higher than that of the control beam. For example, the ultimate load

18 of beam FCSB2-b was $317.65 \mathrm{kN}$, showing a remarkable increase of $103.45 \%$ over the

19 control beam. It can be seen from the comparison of beams FCSB1-a, FCSB1-c and FCSB1-

20 e that the load corresponding to the formation of the first shear crack increased as the pre- 
1 stress level increased. Therefore, the strengthened beam using CFRP-PCPs with higher pre-

2 stress levels can arrest the formation and development of cracks more effectively. This leads

3 to the higher stiffness and load corresponding to the first shear crack than that with lower

4 prestress level. However, the CFRP-PCPs in 50\% prestressed-strengthened beam (FCSB1-

5 e) failed by debonding when the applied load approached the ultimate shear capacity. There-

6 fore, the ultimate load of beam FCSB1-e was slightly lower than that of 30\% prestressed-

7 strengthened beam FCSB1-c due to the debonding of CFRP-PCPs. For the prestressed-

8 strengthened beams with higher prestress levels, the strength of CFRP-PCPs was not fully

9 utilised resulting in only a slight increase in the ultimate load.

10 The results show that the shear strength of the strengthened beams increases with the

11 decrease in spacing of NSM CFRP-PCPs, as the other parameters were kept the same. In

12 comparison to beam FCSB1-b, the ultimate load of beam FCSB2-a was increased by

$1326.33 \%$. The beam FCSB2-b, strengthened with the CFRP-PCPs of $45^{\circ}$ inclination, had a

$14 \quad 19.88 \%$ increase in the ultimate load compared with the beam FCSB1-c, strengthened with

15 vertical CFRP-PCPs. Additionally, the shear strengthening technique with $45^{\circ} \mathrm{NSM}$

16 CFRP-PCPs in beam FCSB2-b effectively averted brittle shear failure and the failure was

17 due to ductile flexure. The shear failure crack tended to be almost vertical to the inclined

$1845^{\circ}$ CFRP-PCPs. Also, the total bonding length of the NSM inclined CFRP-PCPs was

19 higher than that of vertical CFRP-PCPs. These factors contributed to the better shear per-

20 formance of beams with NSM CFRP-PCPs applied at $45^{\circ}$ inclination, which exhibited the

21 highest increase in strength and ductility. The material type of the prisms displayed a slight 
1 effect on the shear behaviour of the strengthened beams through the comparison of load-

2 displacement curves between FCSB1-c and FCSB1-d.

\section{$4 \quad 3.3$ Load-strain relationship in tensile steel bars}

The load versus tensile steel strain relationship for the tested beams is shown in Fig.

6 6. From the initial loading to the formation of the first crack in the beam, the strain in tensile

7 steel increased slowly and had a linear tendency. The crack appeared in the strengthened

8 beams when the load ranged from $35 \mathrm{kN}$ to $40 \mathrm{kN}$. After the concrete cracked, the external

9 load was transferred to the tensile steel bars and the CFRP-PCPs. Therefore, the strain in

10 the tensile steel bars increased rapidly with only a slight increase of applied load. The con-

11 trol beam, CSB, failed in shear-compressive mode at a small tensile steel strain of $1286 \mu \varepsilon$

12 while the tensile steel bars did not yield. For the strengthened beams, the ultimate strain of

13 the tensile steel bars almost reached the yield strain and was higher than that of control beam.

14 This can be explained by the shear strengthening with the NSM CFRP-PCPs, contributing

15 to the crack resistance and the ultimate load. Additionally, the shear strengthening technique

16 converted the brittle pure shear failure to the less brittle failure mode.

\section{Analytical formulation}

The shear strengthening using NSM CFRP-PCPs is a highly effective technique to

21 improve the shear resistance of the shear-deficient RC beams. The mechanical properties of

22 the NSM CFRP-PCPs during the loading process can be considered analogous with that of 
1 shear steel stirrups. This analytical formulation only considered the shear capacity of beams

2 that failed in shear with the rupture of CFRP-PCPs. The beams that failed due to debonding

3 between the CFRP-PCPs and concrete was not included in the formulation due to its com-

4 plicated mechanism. This problem should be researched in future work. According to mod-

5 ern design codes, the shear capacity of the strengthened beams was assumed to be due to

6 the contribution of shear strength provided by different shear resisting components. The

7 nominal shear capacity $\left(V_{n}\right)$ of an RC member strengthened in shear with NSM CFRP com-

8 posites can be obtained using

9

$10 \quad V_{n}=V_{c}+V_{s}+V_{f}$

12 where $V_{c}, V_{s}$, and $V_{f}$ are the nominal strengths provided by the concrete, steel stirrups and

13 CFRP-PCPs, respectively.

14 The contribution of the NSM CFRP-PCPs for the nominal shear capacity of strength-

15 ened beams was calculated by the proposed analytical formulation. The analytical model

16 was based on two cases:

18 Case 1: the contribution of vertical NSM CFRP-PCPs to the shear capacity.

19 The applied load was transferred to the CFRP rod after the rupture of CFRP-PCPs.

20 The strain of CFRP rods in CFRP-PCPs, from the initial loading to the fracture of CFRP-

21 PCPs, is consistent with that of UHPC prisms, i.e. the strain of CFRP rods when the shear 
1 failure occurred in the strengthened beams was assumed to be that of prisms in fracture. The

2 contribution of NSM CFRP-PCPs shear strengthening is expressed as:

$4 \quad V_{f}=\left(\varepsilon_{f} \cdot E_{f} \cdot A_{f}+T_{p}\right) \cdot \frac{h_{0}}{s_{p}}$

$5 \quad T_{p}=\sigma_{p e} A_{f}+f_{p} A_{p}$

$6 \quad \varepsilon_{f}=\left(\frac{T_{p}}{A_{f}}-\sigma_{p e}\right) / E_{f}$

7 where $\varepsilon_{f}$ is the strain of CFRP rods corresponding to the rupture of UHPC prisms, $E_{f}$ is

8 the elastic modulus of CFRP rods, $A_{f}$ is the total area of vertical CFRP rods in the same

9 cross-section of beam, $T_{p}$ is the maximum tension load before the first crack for CFRP-

10 PCPs, $h_{0}$ is the effective height of the tested beam, $S_{p}$ is the spacing of CFRP-PCPs, $\sigma_{p e}$

11 is the effective prestressing stress of CFRP rods, $f_{p}$ is the ultimate strength of UHPC in

12 CFRP-PCPs, $A_{p}$ is the total area of prisms in the same cross-section of the beam.

14 Case 2: the contribution of inclined $\left(45^{\circ}\right)$ NSM CFRP-PCPs to the shear capacity.

15 During the loading process, the shear cracks that formed were nearly vertical to the

16 inclined CFRP-PCPs in the strengthened beams. The analytical formulation for strength-

17 ened beams in Case 2 was proposed based on the calculated model of the beams reinforced

18 with shear bend-up bars in China code [32]. The shear resistance of the NSM CFRP-PCPs

19 at an inclination of $45^{\circ}$ can be calculated as:

$20 V_{f}=0.8 \times\left(f_{f} A_{f}^{\prime}+T_{p}\right) \cdot \sin \alpha$

$21 T_{p}=\sigma_{p e} A_{f}^{\prime}+f_{p} A_{p}^{\prime}$ 
$1 \quad f_{f}=\frac{T_{p}}{A_{f}}-\sigma_{p e}$

2 where $f_{f}$ is the stress in CFRP rods when the beams failed in shear failure, $A_{f}^{\prime}$ is the total

3 area of $45^{\circ} \mathrm{CFRP}$ rods in CFRP-PCPs crossed by the shear cracks, $A_{p}^{\prime}$ is the area of the

4 prisms in CFRP-PCPs crossed by the shear cracks.

5 The analytical formulation is applicable to the beams FCSB1-b and FCSB2-b that

6 failed in shear failure with the rupture of CFRP-PCPs. The analytical values of shear

7 strength provided by the NSM CFRP-PCPs obtained from the proposed equations were

8 compared with the test results, as shown in Table 4. For the beam FCSB1-b, strengthened

9 with vertical CFRP-PCPs spaced at $200 \mathrm{~mm}$, the ratio of experimental value to calculated

10 value was 0.91. Additionally, the ratio of 0.81 was obtained for the beam FCSB2-b,

11 strengthened with $45^{\circ}$ CFRP-PCPs. It can be concluded that the proposed analytical for-

12 mulation is reliable in the prediction of the contribution of NSM CFRP-PCPs in the shear

13 capacity of strengthened beams. However, this research only proposed the analytical for-

14 mulation of beams that failed due to the rupture of CFRP-PCPs and the number of beams

15 with such a failure mode were limited in this study. Hence, further work related to the shear-

16 strengthened beams using the proposed strengthening technique should be conducted to ver-

17 ify the accuracy of the analytical formulation.

195 Conclusions

An experimental study was conducted to investigate the shear performance of RC

21 beams strengthened by NSM CFRP-PCPs. The contributions of the NSM CFRP-PCPs 
1 strengthening technique to the shear capacity was evaluated using an analytical formulation

2 and compared with the experimental results From the experimental and analytical results

3 presented in this research, the following major conclusions can be obtained:

4

5

6

1. The shear capacity of RC beams strengthened significantly by using the NSM CFRP-PCPs technique. A $65.23 \%$ to $103.45 \%$ increase was observed compared to the non-strengthened control beam. The results indicate that the NSM CFRP-PCPs strengthening technique is an effective method for improving the stiffness and the shear capacity of shear-deficient beams.

2. The NSM CFRP-PCPs can delay and prevent the propagation of shear cracks, which enhances the shear capacity and ductility, and the ultimate deflection was also increased substantially compared with the control beam.

3. The experimental results show that the shear capacity and the ultimate deflection were increased when the spacing of the CFRP-PCPs decreased and the level of prestressing increased. The CFRP-PCPs installed at $45^{\circ}$ inclination have also demonstrated a better shear performance than those with vertical setup. The type of material for prisms has an insignificant impact on the shear capacity of the RC beams.

4. The analytical model proposed is only applicable when the beams are failed due to the rupture of CFRP-PCPs. The analytical results agreed well with the test results. The formulation was approved to be reliable and accurate on predicting the shear capacity that strengthened by the NSM CFRP-PCPs. 
5. A further parametric study would be very useful to explore the limitation of the analytical model and formulation for predicting the shear capacity of the RC beam strengthened by the NSM CFRP-PCPs. The analytical model proposed in this study will provide an important reference for future studies.

\section{Acknowledgements}

The authors are grateful for the financial support of the National Nature Science Foun-

8 dation of China (51768008), British Council and Ministry of Education, China (UK-China-

9 BRI Countries Education Partnership Initiative), China Postdoctoral Science Foundation

10 Project (2017M613273XB) and Liuzhou Scientific Research and Technology Development

11 Plan (2017BC40202), Nature Science Foundation of Guangxi Zhuang Autonomous Re-

12 gion (2019JJA160137) and Royal Academy of Engineering - Industrial Fellow-

13 ship(IF)192023). The authors also acknowledge the support of the Innovation Team Support

14 Plan of Guangxi University of Science and Technology in this research work.

\section{References}

17 1. Abdelhak Bousselham and Omar, C., Shear Strengthening Reinforced Concrete 18 Beams with Fiber-Reinforced Polymer: Assessment of Influencing Parameters and 19 Required Research. ACI Structural Journal. 101(2).

20 2. Islam, A.K.M.A., Effective methods of using CFRP bars in shear strengthening of 21 concrete girders. Engineering Structures, 2009. 31(3): p. 709-714.

22 3. Al-Mahmoud, F., et al., Strengthening of RC members with near-surface mounted 23 CFRP rods. Composite Structures, 2009. 91(2): p. 138-147.

24 4. Attari, N., S. Amziane, and M. Chemrouk, Flexural strengthening of concrete 
beams using CFRP, GFRP and hybrid FRP sheets. Construction and Building Materials, 2012. 37: p. 746-757.

3 5. Barros, J.A.O., I.G. Costa, and A. Ventura-Gouveia, CFRP Flexural and Shear Strengthening Technique for RC Beams: Experimental and Numerical Research. Advances in Structural Engineering, 2011. 14(3): p. 551-573.

6. Sharaky, I.A., et al., Flexural response of reinforced concrete (RC) beams strengthened with near surface mounted (NSM) fibre reinforced polymer (FRP) bars. Composite Structures, 2014. 109: p. 8-22.

7. Kuntal, V.S., M. Chellapandian, and S.S. Prakash, Efficient near surface mounted CFRP shear strengthening of high strength prestressed concrete beams - An experimental study. Composite Structures, 2017. 180: p. 16-28.

8. Norris, T., H. Saadatmanesh, and R. Ehsani Mohammad, Shear and Flexural Strengthening of R/C Beams with Carbon Fiber Sheets. Journal of Structural Engineering, 1997. 123(7): p. 903-911.

9. Sharaky, I.A., L. Torres, and H.E.M. Sallam, Experimental and analytical investigation into the flexural performance of $R C$ beams with partially and fully bonded NSM FRP bars/strips. Composite Structures, 2015. 122: p. 113-126.

10. Karzad, A.S., et al., Repair and strengthening of shear-deficient reinforced concrete beams using Carbon Fiber Reinforced Polymer. Composite Structures, 2019. 223: p. 110963.

11. Afefy, H.M., K. Sennah, and H. Akhlagh-Nejat, Experimental and analytical investigations on the flexural behavior of CFRP-strengthened composite girders. Journal of Constructional Steel Research, 2016. 120: p. 94-105.

12. Wu, G., et al., Performance and Parametric Analysis of Flexural Strengthening for RC Beams with NSM-CFRP Bars. Journal of Composites for Construction, 2014. 18(4).

13. Lim, D.H., Shear behaviour of RC beams strengthened with NSM and EB CFRP strips. Magazine of Concrete Research, 2010. 62(3): p. 211-220.

14. Zhou, Y., et al., Shear strength components of adjustable hybrid bonded CFRP shear-strengthened RC beams. Composites Part B: Engineering, 2019. 163: p. 3651.

15. Dias, S.J.E. and J.A.O. Barros, NSM shear strengthening technique with CFRP laminates applied in high T cross section RC beams. Composites Part B: Engineering, 2017. 114: p. 256-267. 
1 16. Rahal, K.N. and H.A. Rumaih, Tests on reinforced concrete beams strengthened in shear using near surface mounted CFRP and steel bars. Engineering Structures, 2011. 33(1): p. 53-62.

17. Raafat El-Hacha and Sami, H.R., Near-Surface-Mounted Fiber-Reinforced Polymer Reinforcements for Flexural Strengthening of Concrete Structures. ACI Structural Journal. 101(5).

18. Al-Mahmoud, F., et al., Reinforced Concrete Beams Strengthened with NSM CFRP Rods in Shear. Advances in Structural Engineering, 2015. 18(10): p. 1563-1574.

19. Dias, S.J.E. and J.A.O. Barros, Performance of reinforced concrete T beams

20. Badawi, M. and K. Soudki, Flexural strengthening of $R C$ beams with prestressed

21. de Albornoz, V.A.C., et al., Experimental Study of a New Strengthening Technique

22. El-Hacha, R. and M. Gaafar, Flexural strengthening of reinforced concrete beams using prestressed, near-surface-mounted CFRP bars. Pci Journal, 2011: p. 134151.

23. Hajihashemi, A., D. Mostofinejad, and M. Azhari, Investigation of RC Beams Strengthened with Prestressed NSM CFRP Laminates. Journal of Composites for Construction, 2011. 15(6): p. 887-895.

24. Jung, W.T., et al., Flexural Behaviour of RC Beams Strengthened with Prestressed CFRP NSM Tendon Using New Prestressing System. International Journal of Polymer Science, 2017.

25. Davoudi, S., D. Svecova, and C. Gheorghiu, Carbon Fiber-Reinforced Polymer Prestressed Prisms as Reinforcement in Continuous Concrete T-Beams. ACI Structural Journal, 2008. 105(3): p. pp 368-374.

26. Liang, J.-F., et al., Flexural behaviour of reinforced concrete beams strengthened with NSM CFRP prestressed prisms. Structural Engineering and Mechanics, 2017. 62(3): p. 291-295.

27. Liang, J.F., D. Yu, and B. Yu, Flexural behavior of concrete beams reinforced with CFRP prestressed prisms. Computers and Concrete, 2016. 17(3): p. 295-304. 
1 28. Svecova, D., A.G. Razaqpur, and I. American Concrete, Flexural Behavior of Concrete Beams Reinforced with Carbon Fiber-Reinforced Polymer (CFRP) Prestressed Prisms. ACI Structural Journal, 2000. 97(5): p. p. 731-738.

29. Kuntal V S, Chellapandian M, Prakash S S, et al. Efficient near surface mounted CFRP shear strengthening of high strength prestressed concrete beams - An experimental study, Composites Structures,2017 . 180: p. 16-28.

30. Dias, S.J.E., and Barros, J.A.O., Shear Strengthening of RC T-Section Beams with Low Strength Concrete Using NSM CFRP Laminates. Cement and Concrete Composites, 2011. 33(2):p. 334-345.

31. Dias, S.J.E., and Barros, J.A.O., Shear Strengthening of RC Beams with NSM CFRP Laminates: Experimental Research and Analytical Formulation. Composites Structures, 2013. 99:p. 477-490.

32. Kuntal V S, Chellapandian M, Prakash S S, et al. Experimental Study on the Effectiveness of Inorganic Bonding Materials for Near-Surface Mounting Shear Strengthening of Prestressed Concrete Beams. Fibers, 2020, 8(6):p. 40.

33. The national standard of the People's Republic of China. Code for design of concrete structures (GB50010-2010). Beijing: China Architecture \& Building Press, 2015.

34. The national standard of the People's Republic of China. Code for testing method for mechanical properties of ordinary concrete. (GB/T 50081-2002). Beijing: China Architecture \& Building Press, 2002.

35. The national standard of the People's Republic of China. CMetallic Materials: Tensile tests, Part 1: Method of test at room temperature. (GB/T 228.1-2010). Beijing: China Architecture \& Building Press, 2010.

36. The national standard of the People's Republic of China. Code for Reactive Power Concrete. (GB/T 31387-2015). Beijing: China Architecture \& Building Press, 2015.

37. The national standard of the People's Republic of China. Method of Testing Cements - Determination of Strength. (GB/T 17671-1999). Beijing: China Architecture \& Building Press, 1999. 


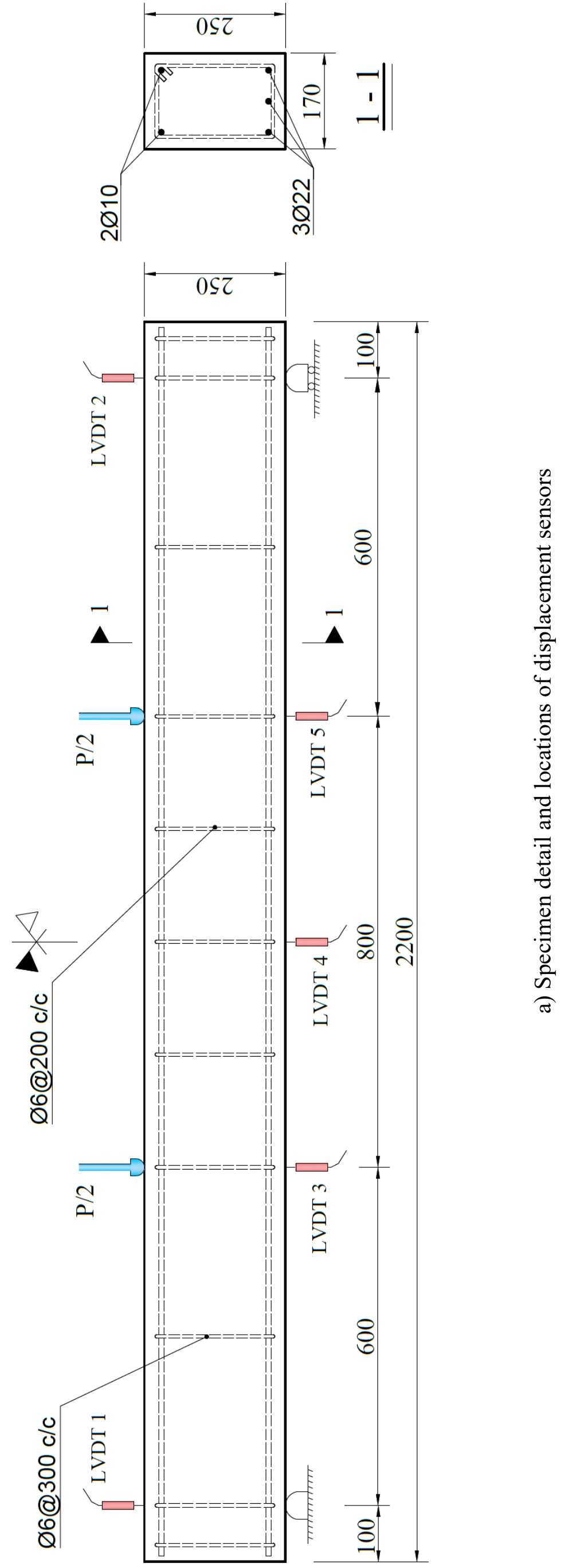




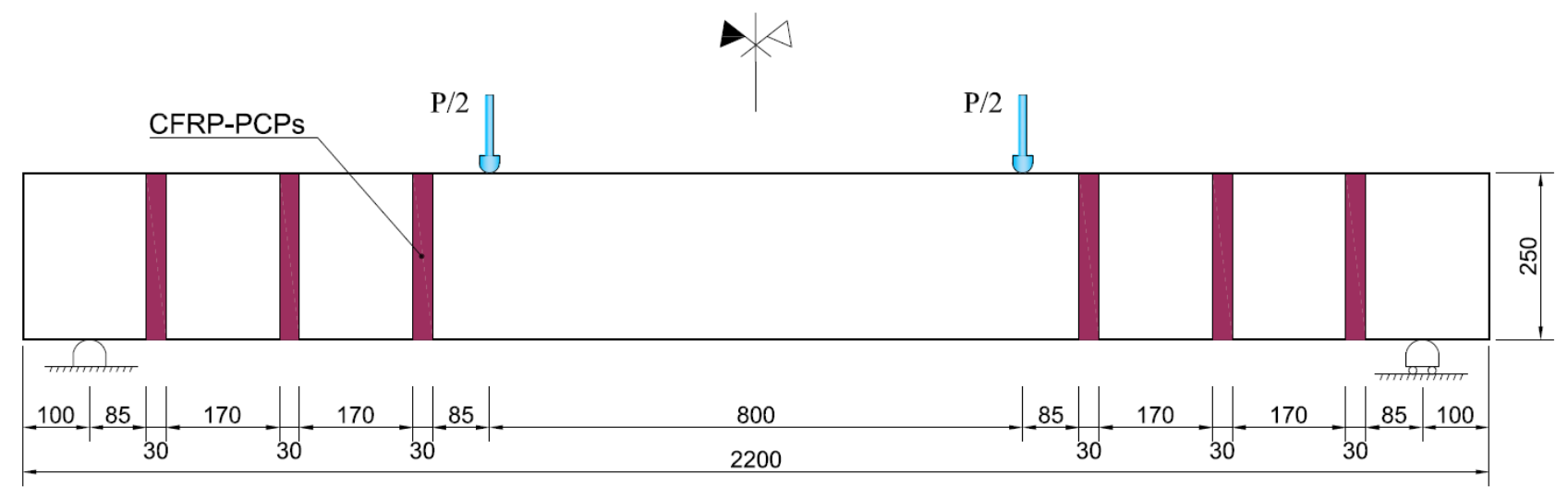

b) Beams FCSB1-a、FCSB1-c、FCSB1-d、FCSB1-e.

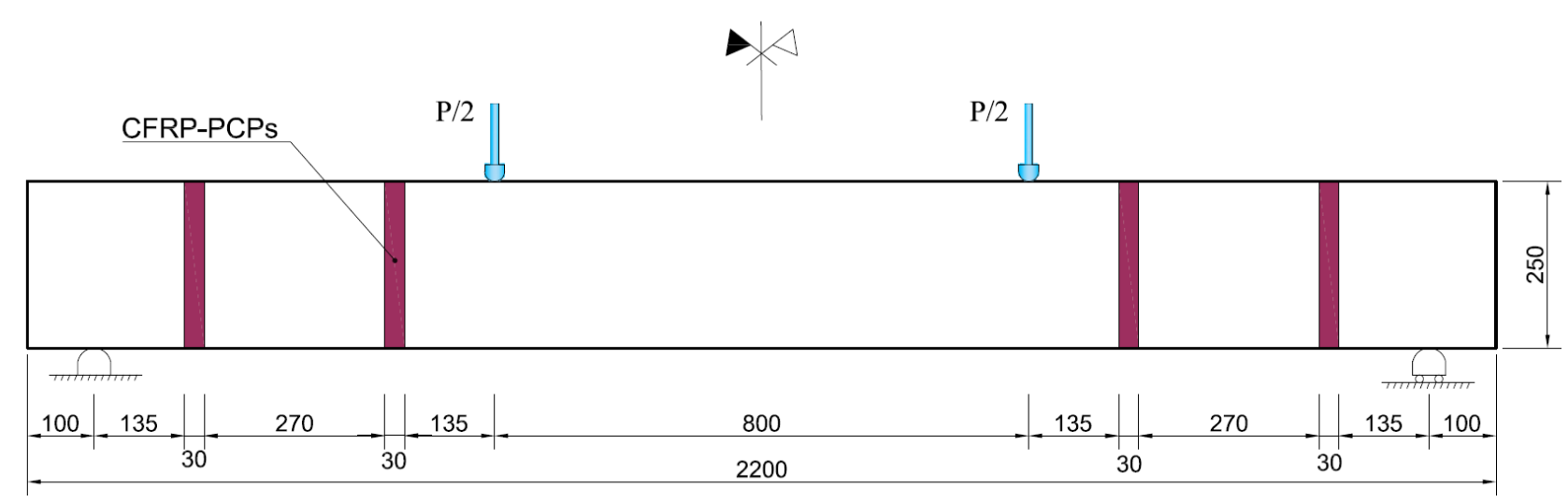

c) Beam FCSB1-b

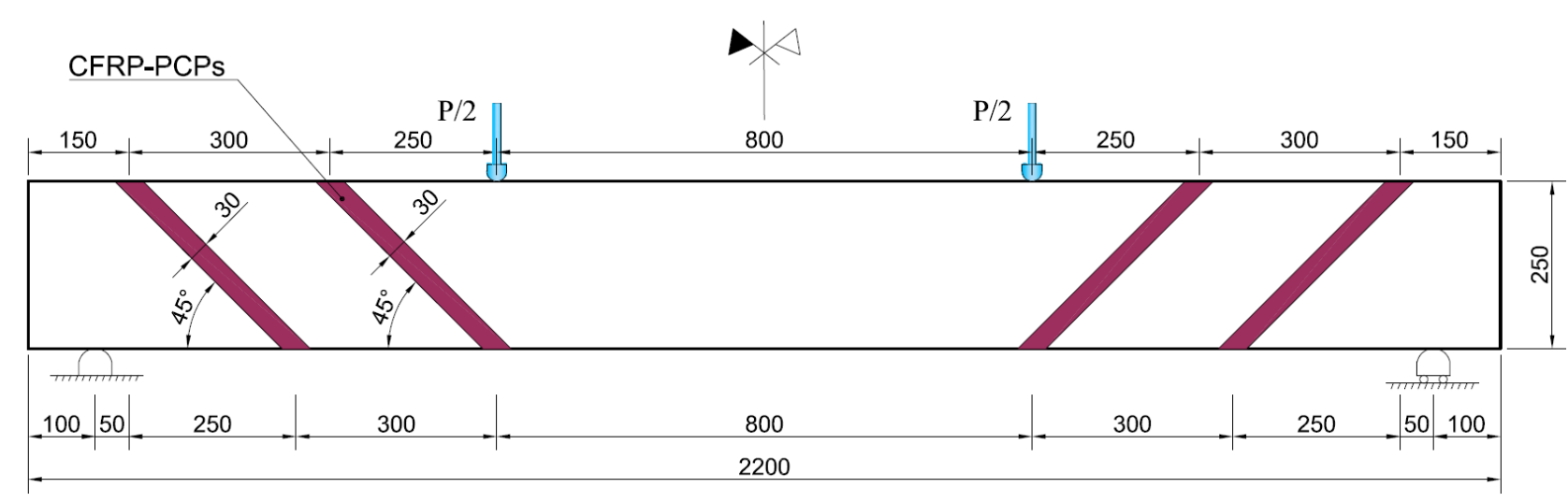

d) Beam FCSB2-a

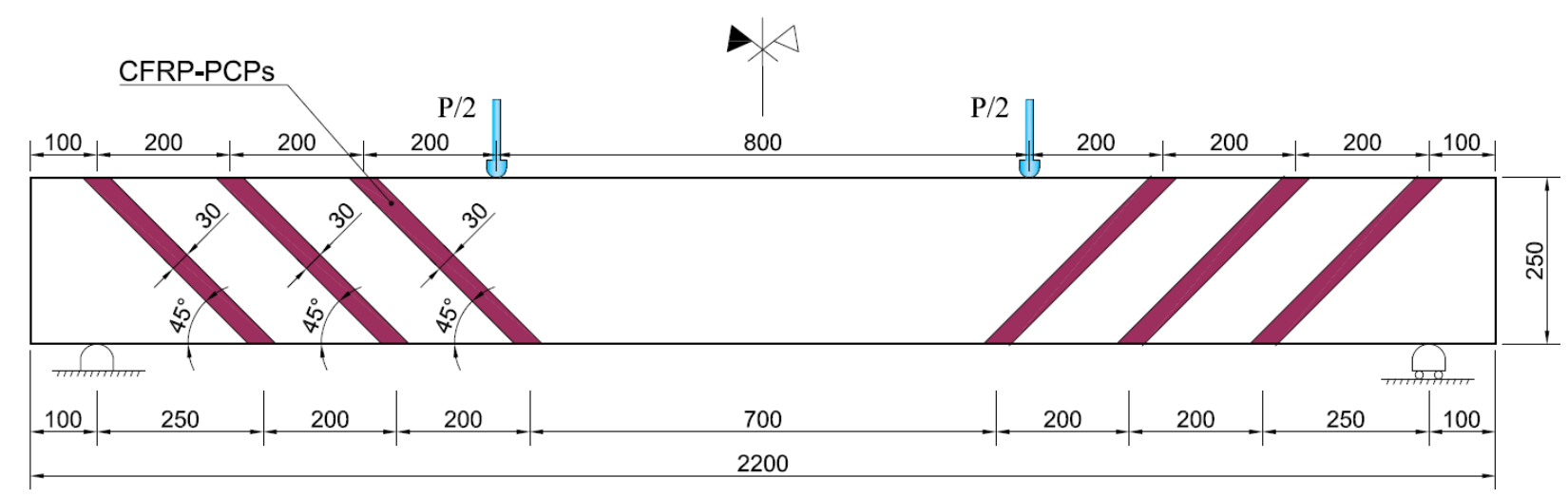

e) Beam FCSB2-b

Fig.1a-e. Specimen design and shear strengthening configurations using NSM CFRP-PCPs (mm) 


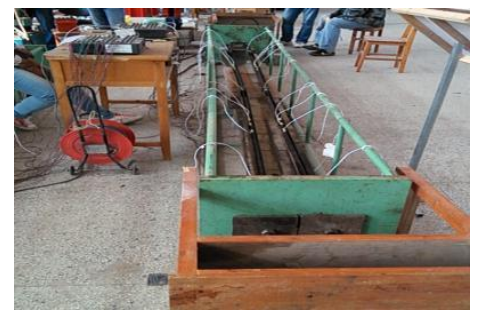

a) Installation of CFRP rods.

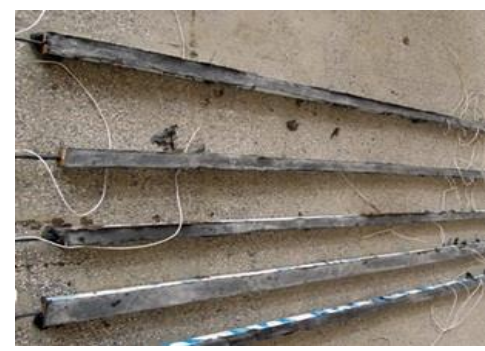

d) The finished CFRP-PCPs.

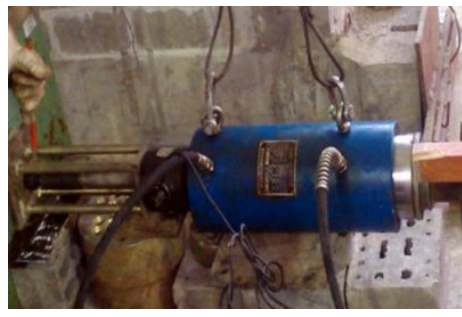

b) Prestressing the CFRP rods.

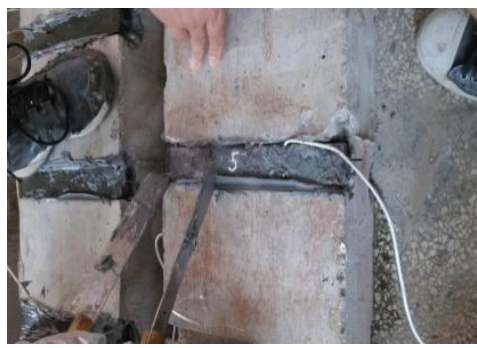

e) Strengthening procedure.

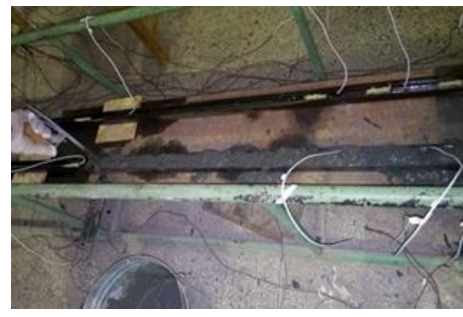

c) Pouring the concrete.

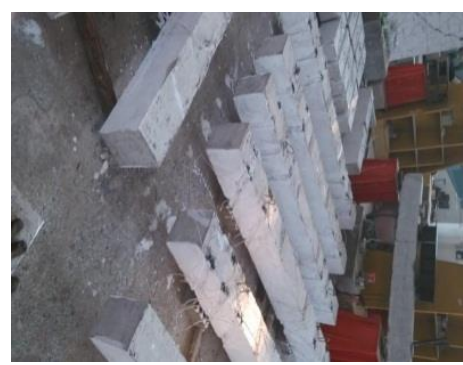

f) Strengthened beams.

Fig. 2. The fabrication of CFRP-PCPs and NSM strengthening process.

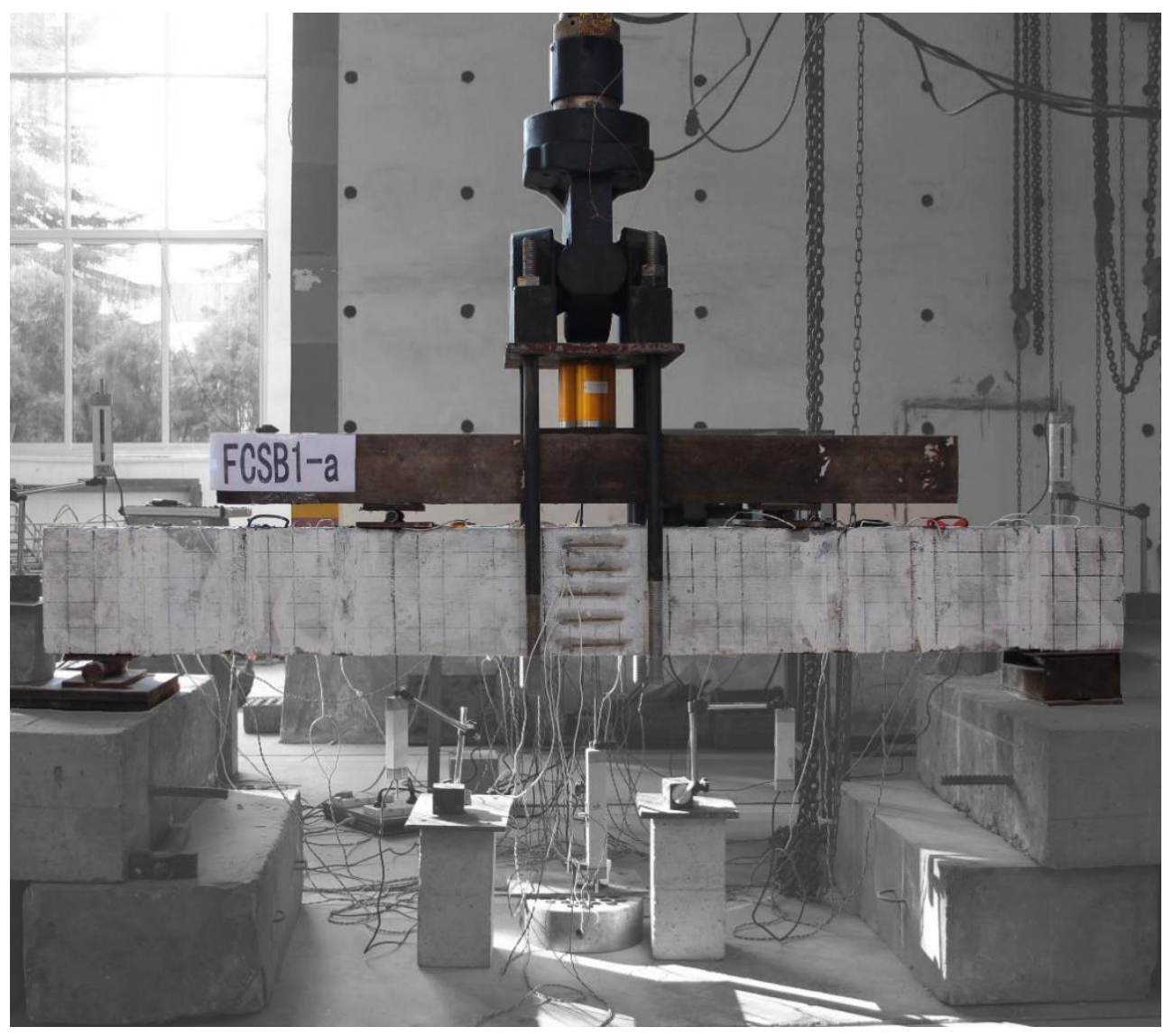

Fig. 3. The test setup and instrumentation 


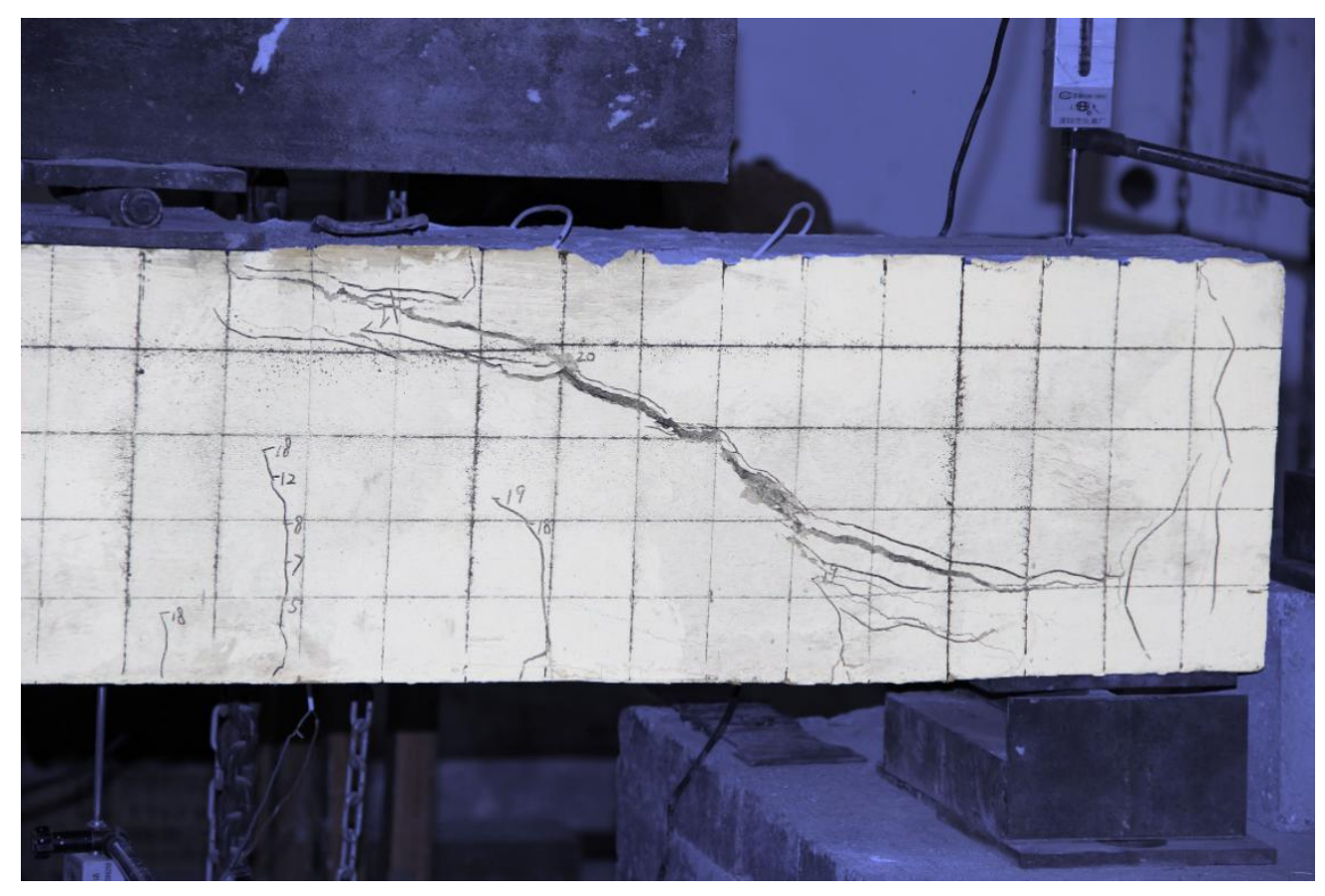

a) Control beam

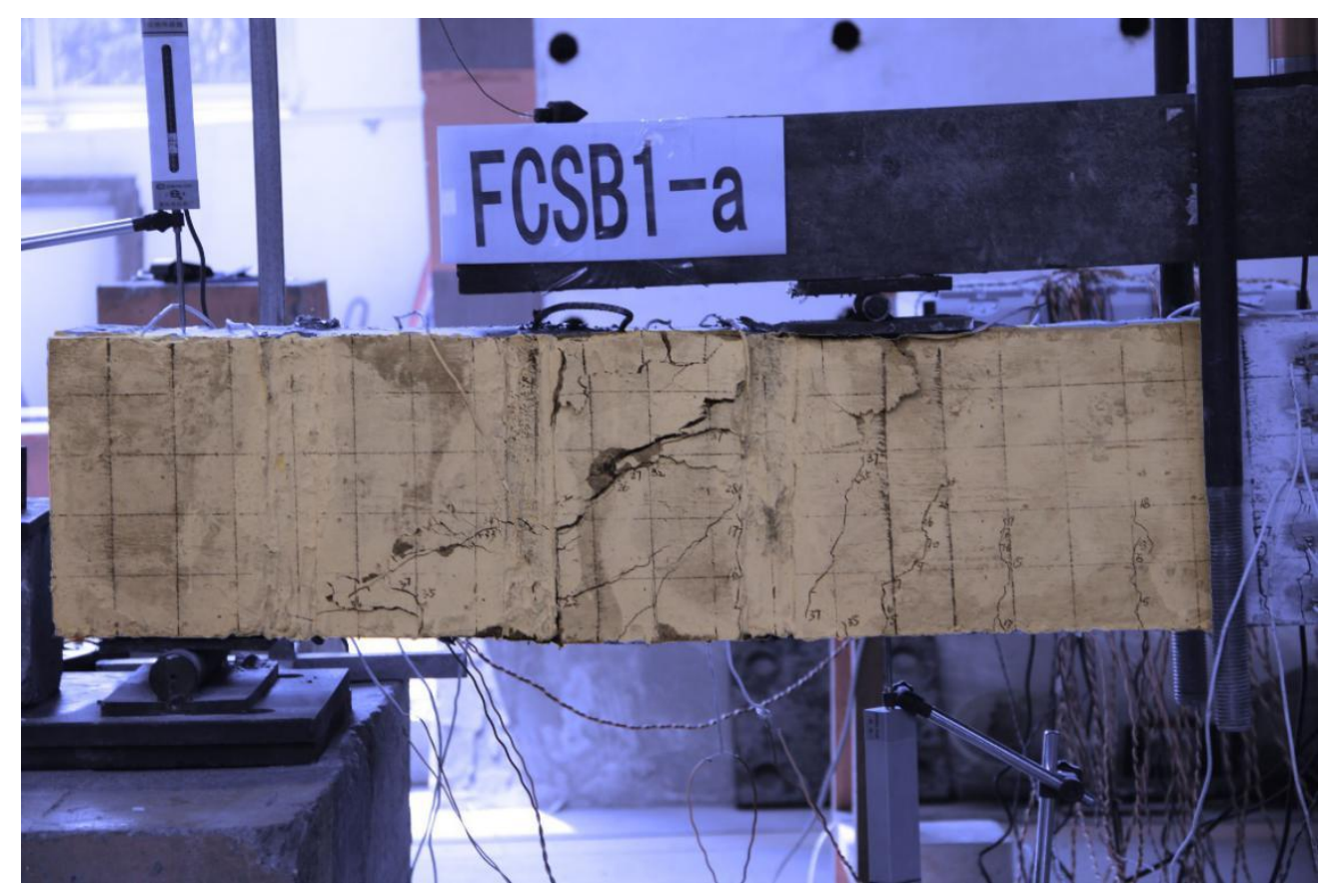

b) Beam FCSB1-a 


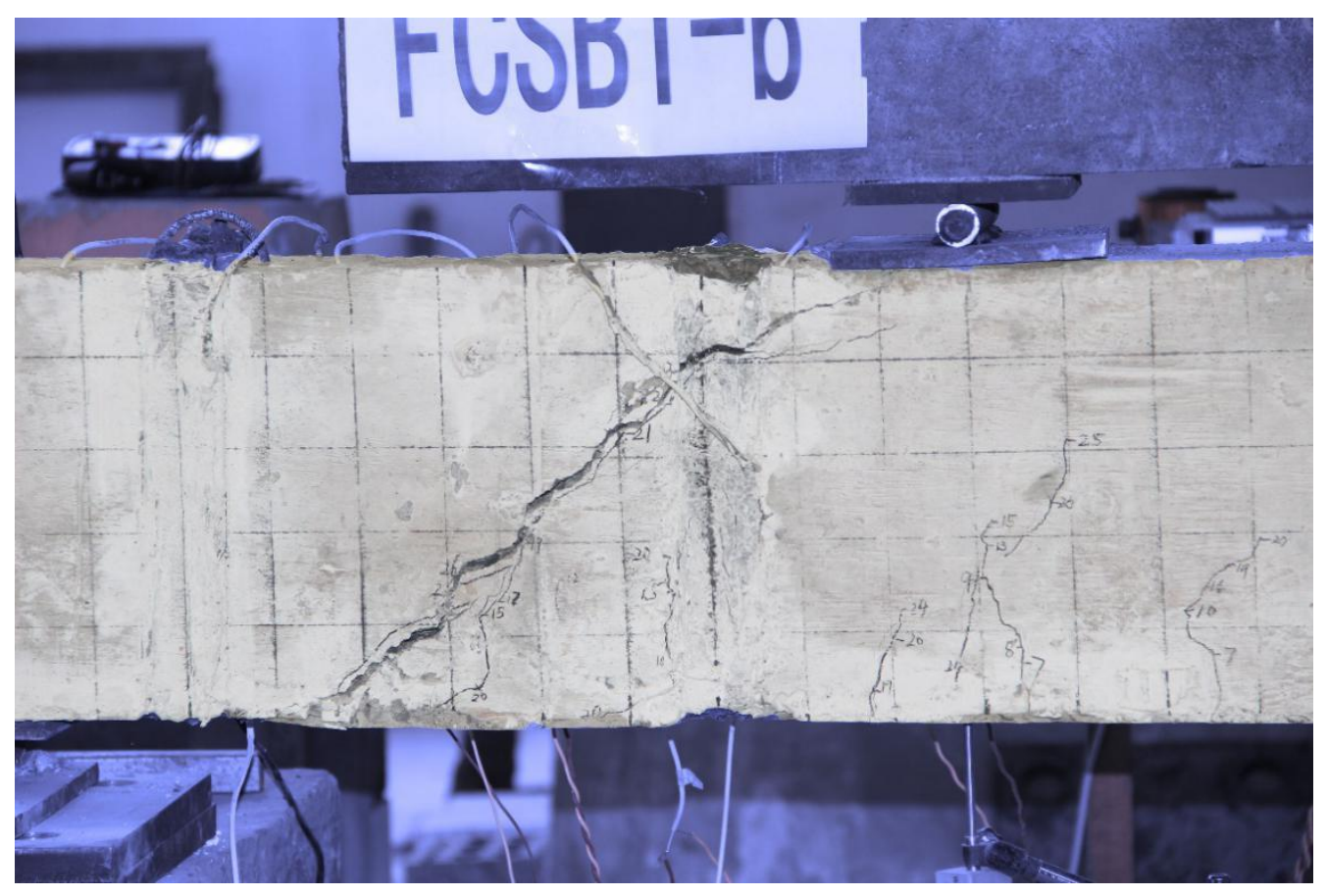

c) Beam FCSB1-b

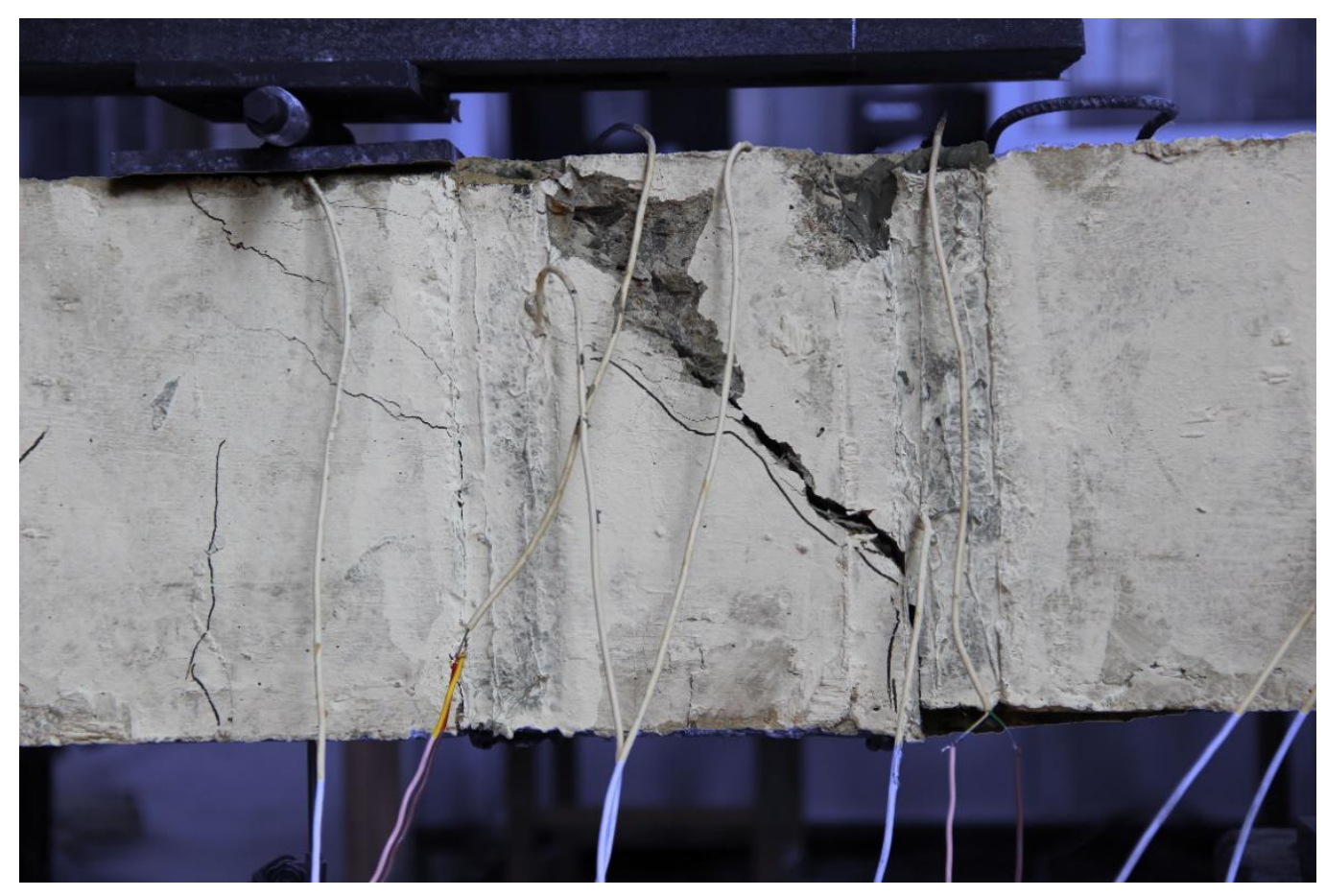

d) Beam FCSB1-c 


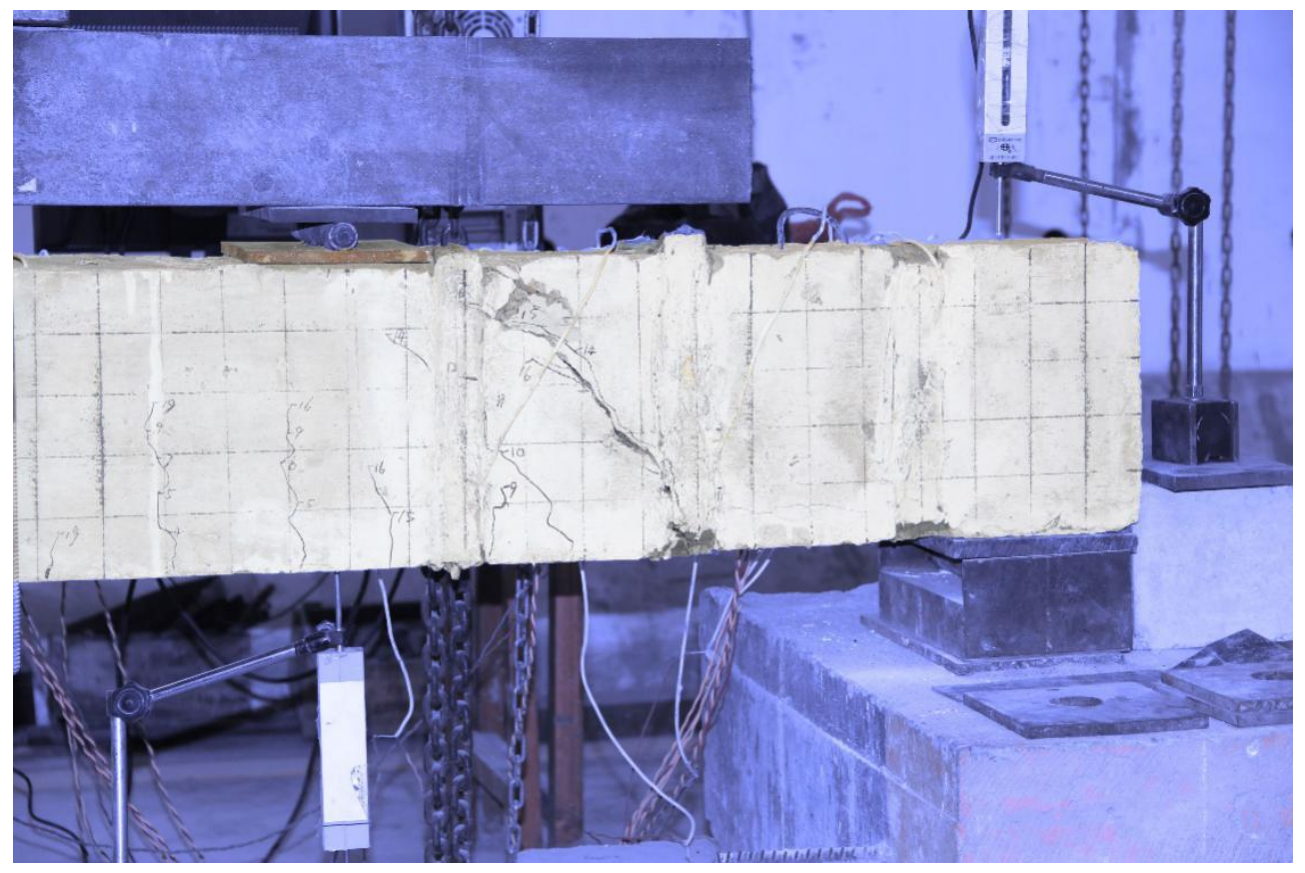

e) Beam FCSB1-d

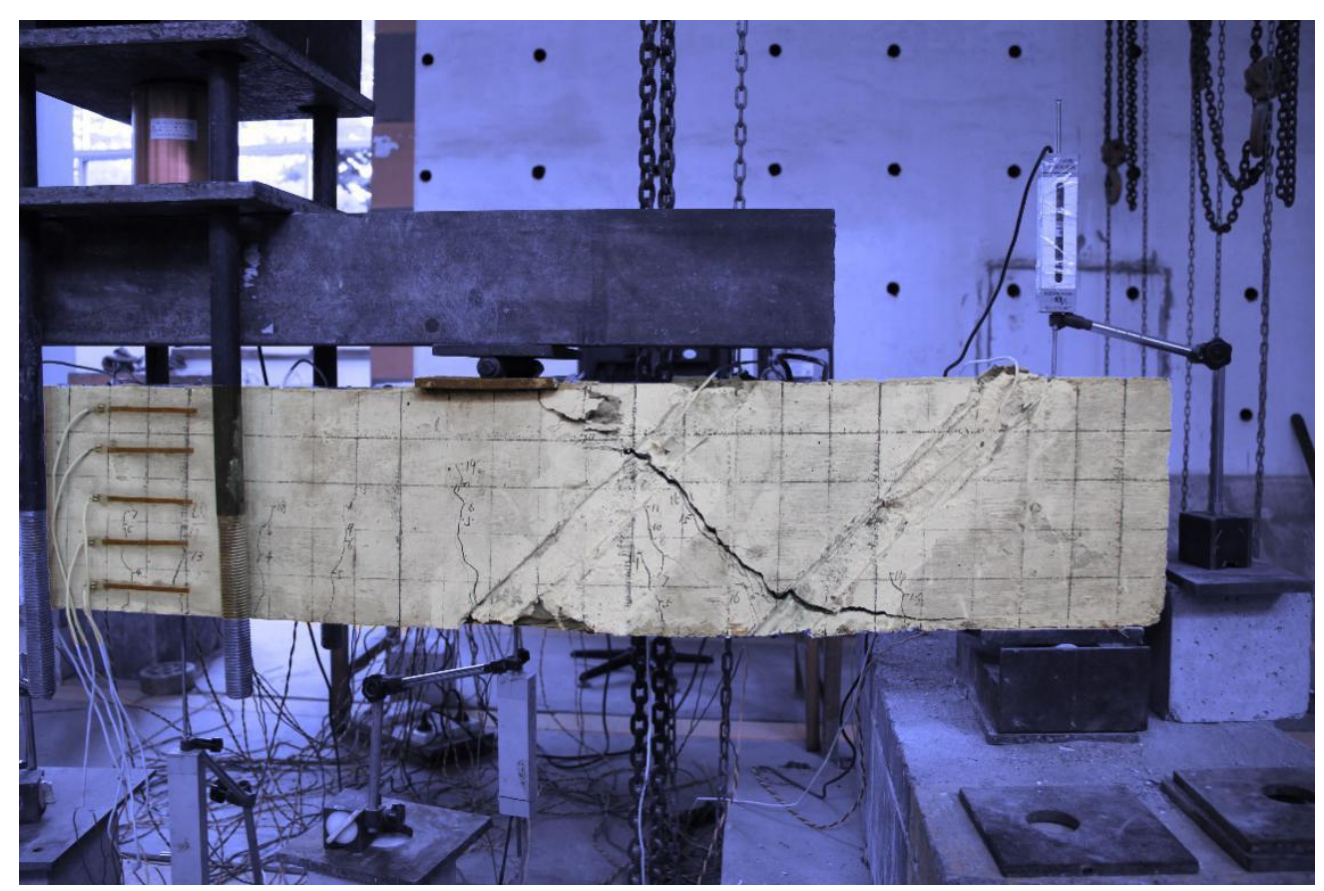

f) Beam FCSB2-a 


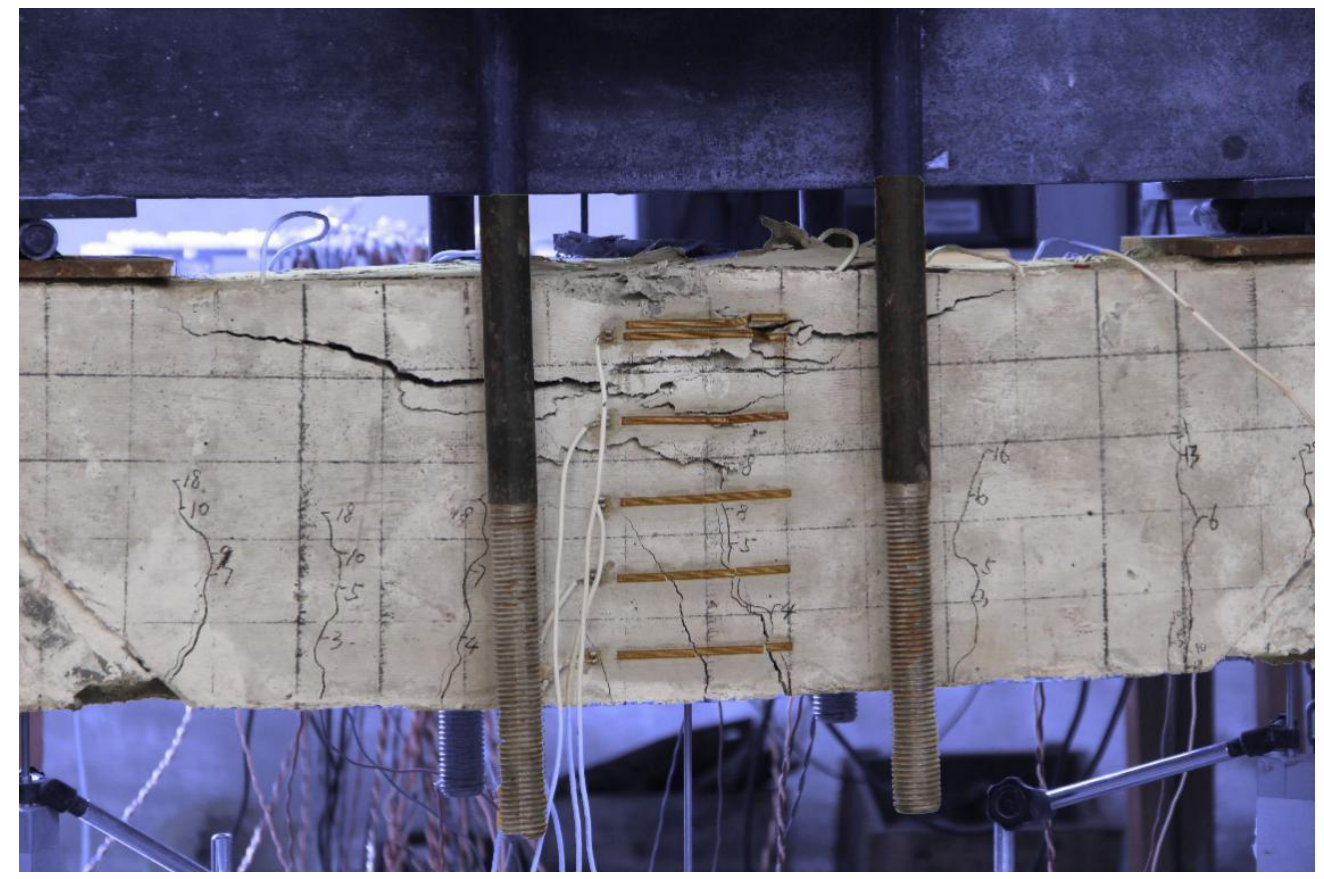

g) Beam FCSB2-b

Fig. 4a-g. Failure pattern of control beam and shear strengthened beams

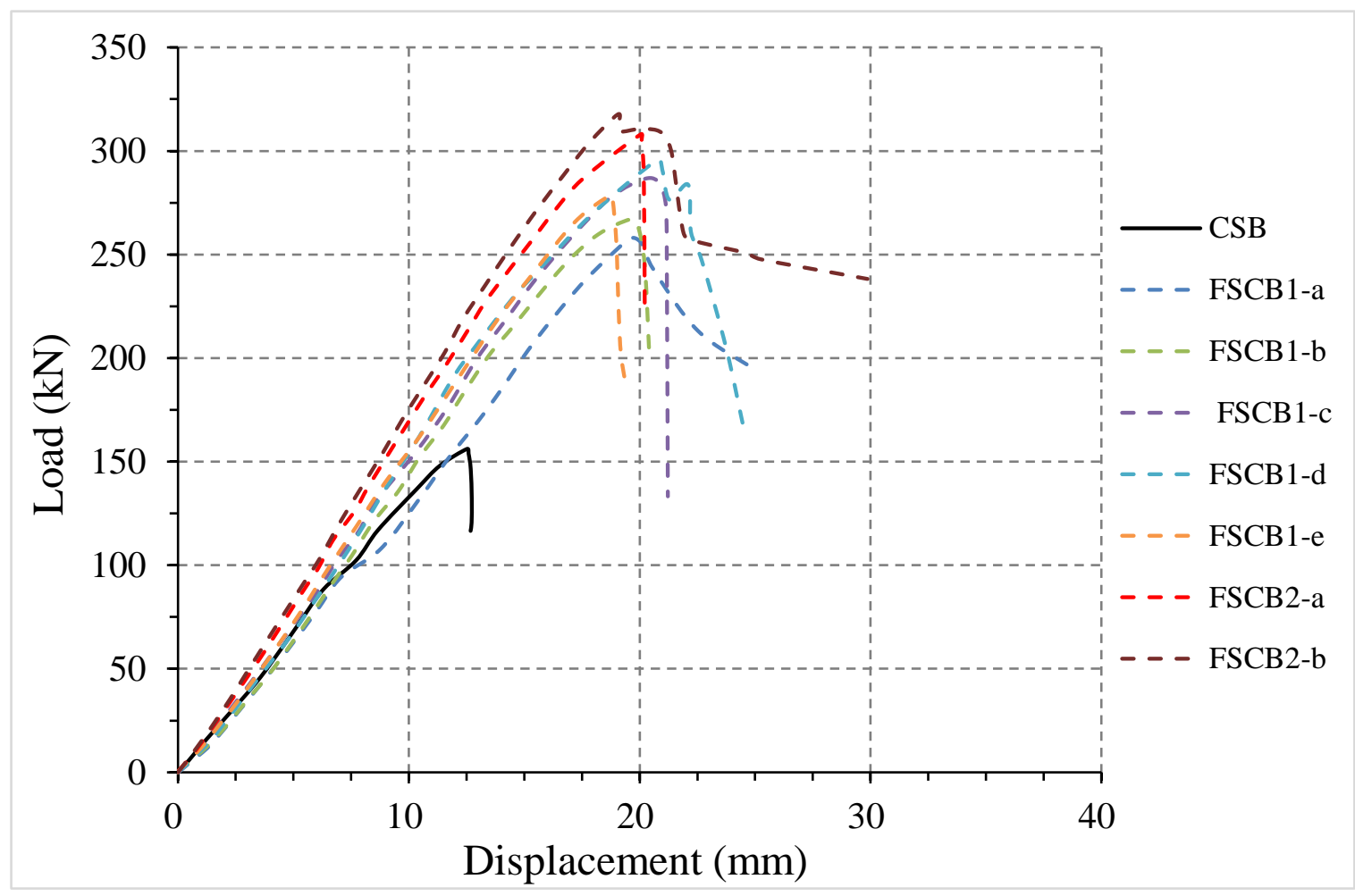

Fig. 5. The load versus displacement relationship of the tested beams 


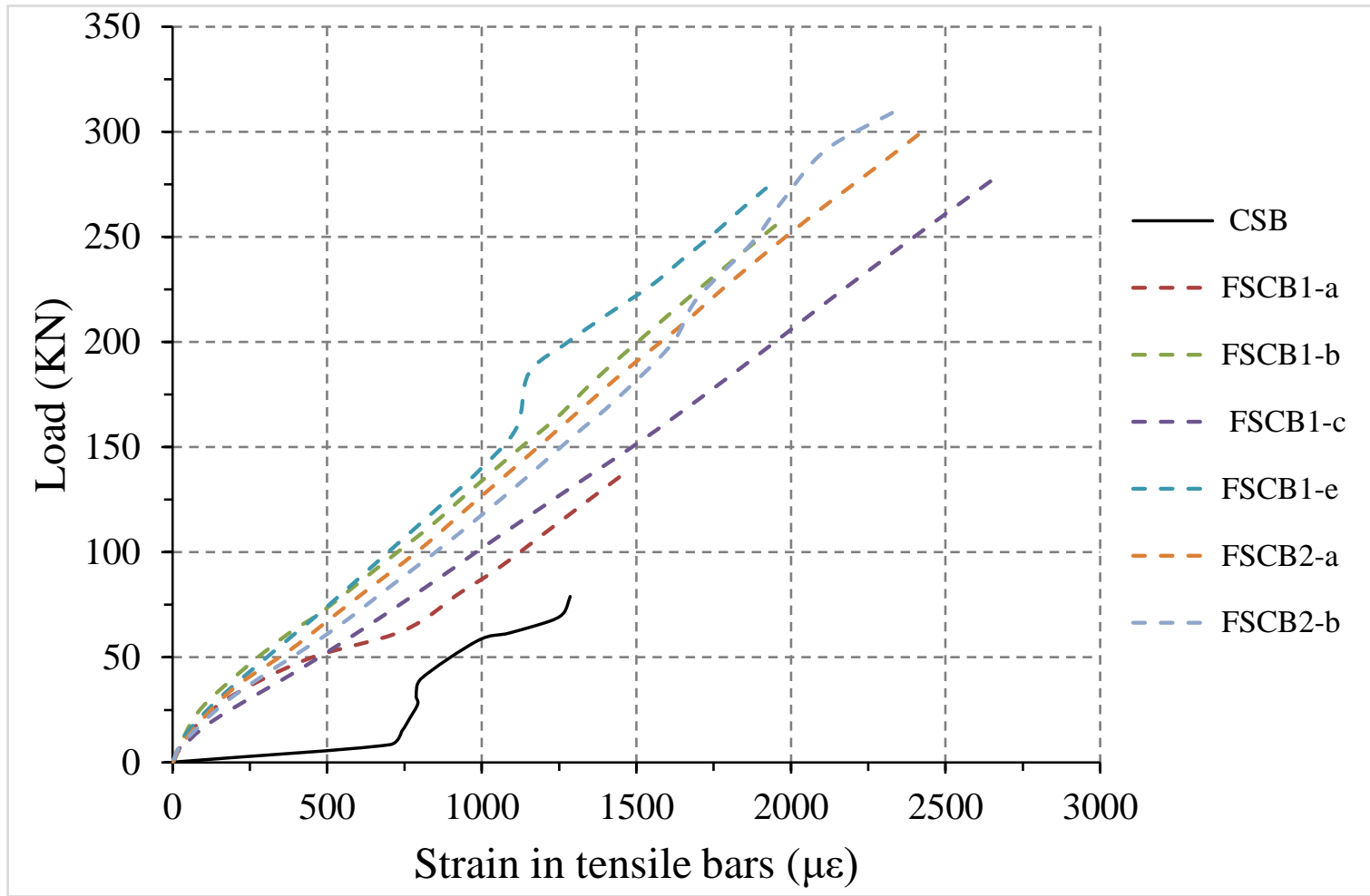

Fig. 6. The load versus strain relationship in tensile steel bars 
Table 1: Fabrication details and parameters of the tested beams

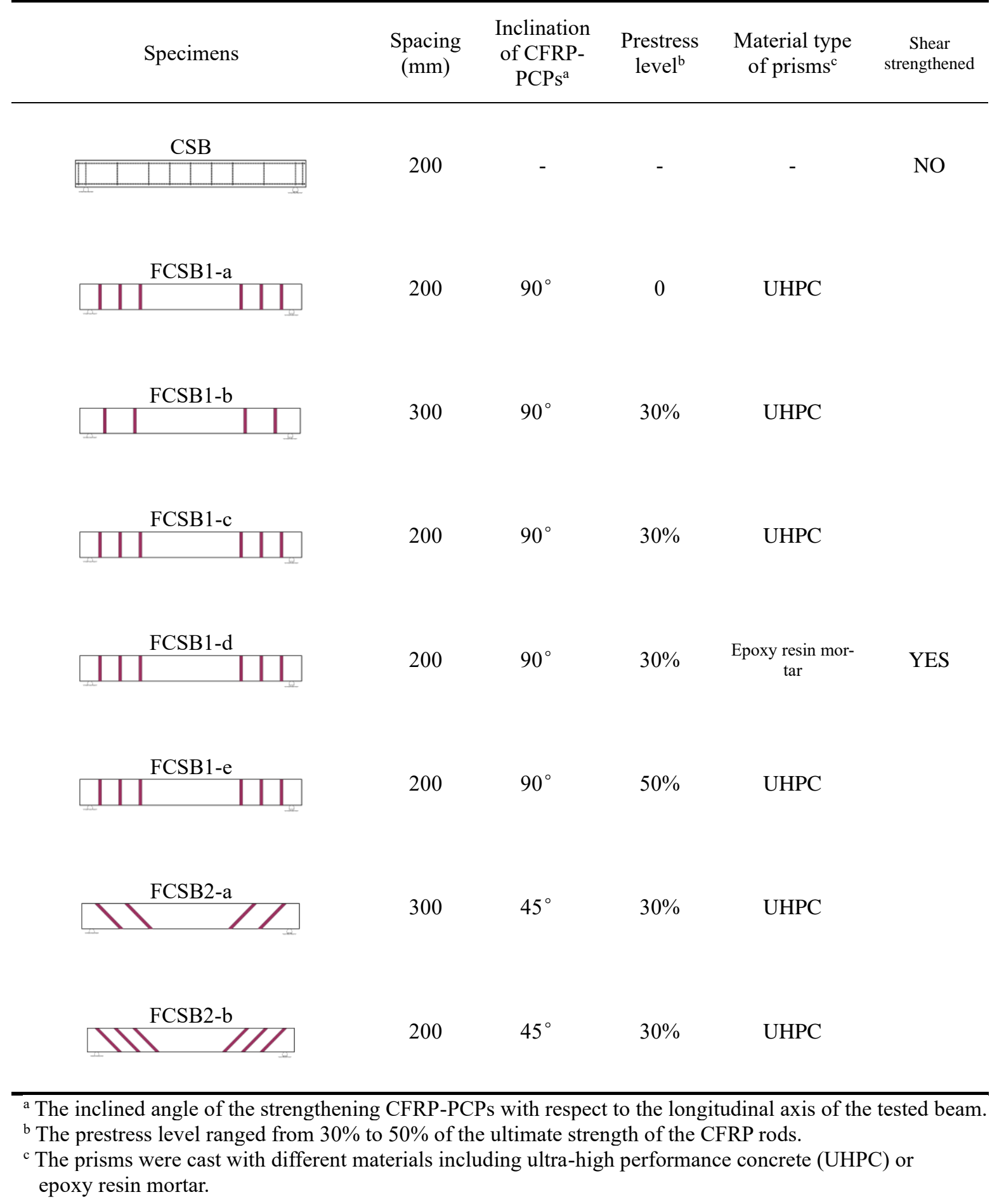


Table 2: Mechanical properties of materials

\begin{tabular}{|c|c|c|c|c|c|}
\hline \multicolumn{2}{|c|}{ Materials } & $\begin{array}{c}\text { Modulus of elasticity } \\
\text { (GPa) } \\
{[\mathrm{cov}]^{\mathrm{a}}}\end{array}$ & $\begin{array}{c}\text { Compressive strength } \\
(\mathrm{MPa}) \\
{[\mathrm{cov}]}\end{array}$ & $\begin{array}{c}\text { Tensile strength } \\
\text { (MPa) } \\
{[\mathrm{cov}]}\end{array}$ & $\begin{array}{l}\text { Yield strength } \\
\text { (MPa) } \\
{[\mathrm{cov}]}\end{array}$ \\
\hline \multicolumn{2}{|c|}{ Concrete [34] } & $\begin{array}{c}32.7 \\
{[14.7 \%]}\end{array}$ & $\begin{array}{c}30.76 \\
{[13.3 \%]}\end{array}$ & $\begin{array}{c}3.02 \\
{[14.4 \%]}\end{array}$ & - \\
\hline \multirow{3}{*}{$\begin{array}{c}\text { Steel bars } \\
\text { [35] }\end{array}$} & $\Phi 22$ & $\begin{array}{c}211 \\
{[5.7 \%]}\end{array}$ & - & $\begin{array}{c}665 \\
{[2.4 \%]}\end{array}$ & $\begin{array}{c}465 \\
{[2.2 \%]}\end{array}$ \\
\hline & $\Phi 10$ & $\begin{array}{c}221 \\
{[6.2 \%]}\end{array}$ & - & $\begin{array}{c}620 \\
{[2.6 \%]}\end{array}$ & $\begin{array}{c}445 \\
{[2.8 \%]}\end{array}$ \\
\hline & $\Phi 6$ & $\begin{array}{c}207 \\
{[4.1 \%]}\end{array}$ & - & $\begin{array}{c}610 \\
{[6.5 \%]}\end{array}$ & $\begin{array}{c}424 \\
{[6.3 \%]}\end{array}$ \\
\hline \multicolumn{2}{|c|}{ CFRP rod ${ }^{b}$} & 155 & & 2400 & $2000^{c}$ \\
\hline \multicolumn{2}{|c|}{ UHPC [36] } & $\begin{array}{c}43.5 \\
{[11.5 \%]}\end{array}$ & $\begin{array}{c}154 \\
{[12.5 \%]}\end{array}$ & $\begin{array}{c}17.4 \\
{[12.2 \%]}\end{array}$ & - \\
\hline \multicolumn{2}{|c|}{$\begin{array}{c}\text { Epoxy resin mortar } \\
{[37]}\end{array}$} & $\begin{array}{c}85 \\
{[7.2 \%]}\end{array}$ & $\begin{array}{c}75 \\
{[7.5 \%]}\end{array}$ & $\begin{array}{c}20 \\
{[7.4 \%]}\end{array}$ & - \\
\hline
\end{tabular}

${ }^{a}[\operatorname{cov}]$ is the coefficient of variation.

${ }^{\mathrm{b}}$ Mechancial properties specified in the Product Quality Certifications provided by the manufacturer, OVM Machinery Co. Ltd (http://www.ovm.cn/).

${ }^{c}$ The nominal yield strength of CFRP rods, equivalent to $85 \%$ of the ultimate strength, prewarning upper limit in practical design. 
Table 3: Experimental results of the tested beams

\begin{tabular}{cccc}
\hline Specimen & Ultimate load $(\mathrm{kN})$ & Improvement $^{\mathrm{a}}(\%)$ & Failure mode \\
\hline CSB & 156.13 & - & \\
FCSB1-a & 257.97 & 65.23 & \\
FCSB1-b & 266.93 & 70.97 & Shear-tension \\
FCSB1-c & 286.61 & 83.57 & \\
FCSB1-d & 295.67 & 89.37 & \\
FCSB1-e & 278.69 & 78.5 & \\
FCSB2-a & 308.05 & 97.3 & \\
FCSB2-b & 317.65 & 103.45 &
\end{tabular}

a The improvement in ultimate load of the shear-strengthened beams compared with the control beam.

${ }^{\mathrm{b}}$ The beam FCSB1-e failed in shear-compression failure and debonding failure.

Table 4: Comparison between the experimental and analytical values of shear strength

\begin{tabular}{|c|c|c|c|c|c|c|}
\hline \multirow{2}{*}{ Specimen } & \multicolumn{2}{|c|}{ Experimental values $(\mathrm{kN})$} & \multicolumn{2}{|c|}{ Analytical values $(\mathrm{kN})$} & \multicolumn{2}{|c|}{ Ratio } \\
\hline & $V_{f}$ & $V_{n}$ & $V_{f}^{\prime}$ & $V_{n}^{\prime}$ & $V_{f} / V_{f}^{\prime}$ & $V_{n} / V_{n}^{\prime}$ \\
\hline $\mathrm{CSB}$ & - & 156.13 & - & 136.81 & - & 1.14 \\
\hline FCSB1-b & 110.80 & 266.93 & 121.28 & 258.09 & 0.91 & 1.03 \\
\hline FCSB2-a & 151.92 & 308.05 & 187.07 & 323.88 & 0.81 & 0.95 \\
\hline FCSB2-b & - & 317.65 & - & 315.38 & - & 1.01 \\
\hline
\end{tabular}

